\title{
Brolucizumab-related intraocular inflammation in Japanese patients with age-related macular degeneration: a short-term multicenter study
}

\author{
Ichiro Maruko ${ }^{1}$ (D) Annabelle A. Okada ${ }^{2} \cdot$ Tomohiro lida $^{1} \cdot$ Taiji Hasegawa $\cdot$ Takahiko Izumi • Moeko Kawai • \\ Ruka Maruko - Makiko Nakayama • Akiko Yamamoto • Hideki Koizumi • Tamaki Tamashiro • Nobuhiro Terao • \\ Sorako Wakugawa · Ryusaburo Mori • Hajime Onoe • Koji Tanaka • Yu Wakatsuki • Kanako Itagaki • Akihito Kasai • \\ Masashi Ogasawara • Tetsuju Sekiryu • Hiroaki Shintake • Yukinori Sugano • for the Japan AMD Research Consortium
}

Received: 13 January 2021 / Revised: 20 February 2021 / Accepted: 26 February 2021 / Published online: 15 March 2021

(C) The Author(s) 2021

\section{Key messages}

\section{What is known}

- Brolucizumab-related intraocular inflammation occurred more frequently in Japanese patients with age-related macular degeneration, compared to other patients in phase 3 global clinical trials.

\section{New information}

- Between 9 and $10 \%$ of both treatment-naive and switched Japanese patients in our study developed intraocular inflammation after brolucizumab administration.

- Of patients with intraocular inflammation, 75\% developed it at a mean of $23.2 \pm 9.3$ (range 10-36) days after the first brolucizumab injection.

- Rates of intraocular inflammation were not higher in women.

- Inflammation resolved within 2 months.

\section{Dear Editor,}

We report short-term data on the development of intraocular inflammation (IOI) after intravitreal brolucizumab injection for exudative age-related macular degeneration (AMD) in Japanese patients in this letter.

Ichiro Maruko

imaruko@twmu.ac.jp

1 Department of Ophthalmology, Tokyo Women's Medical University School of Medicine, Tokyo, Japan

2 Department of Ophthalmology, Kyorin University School of Medicine, Tokyo, Japan
Brolucizumab (Novartis Pharma AG, Basel, Switzerland), a new anti-vascular endothelial growth factor (VEGF) agent for the treatment of exudative AMD, differs from previous anti-VEGF agents by its smaller molecular weight allowing administration at high concentrations and presumably improved tissue penetration. In the HAWK and HARRIER studies, brolucizumab was reportedly non-inferior to aflibercept in terms of visual outcomes and more effective in reducing intraretinal and subretinal fluid [1]. Early US reports regarding the adverse effect of IOI [2] prompted a Novartis-appointed Safety Review Committee (SRC) to re-evaluate data from the clinical trials [3]. At the 2020 Annual Meeting of the American Academy of Ophthalmology, Heier et al. [4] described SRC findings suggesting that female gender and Japanese ethnicity were risk factors. 
Table 1 Characteristics of 127 eyes of 127 patients treated with intravitreal brolucizumab injection for exudative age-related macular degeneration

\begin{tabular}{lll}
\hline & & $n(\%)$ \\
\hline Gender & Male & $109(85.8 \%)$ \\
& Female & $18(14.2 \%)$ \\
Treatment-naive & & $43(33.9 \%)$ \\
Switched & $84(66.1 \%)$ \\
IOI & $12 / 127(9.4 \%)$ \\
IOI with retinal vasculitis & $4 / 127(3.1 \%)$ \\
IOI with retinal vasculitis and retinal vascular occlusion & $2 / 127(1.6 \%)$ \\
\hline
\end{tabular}

Treatment-naive $=$ eyes without any prior treatment

Switched $=$ eyes previously treated with other anti-VEGF agents

VEGF = vascular endothelial growth factor

IOI = intraocular inflammation

Brolucizumab was approved in Japan in May 2020 and used to treat 149 eyes of 149 patients over the 6-month period May-November 2020 by the Japan AMD Research Consortium. Clinical data for 127 eyes of 127 consecutive patients who had at least 1 follow-up visit after the first brolucizumab injection were retrospectively analyzed. Fortythree patients were treatment-naive ( 36 men, 7 women) and 84 patients were switched from other anti-VEGF agents (73 men, 11 women).

Mean follow-up after the first brolucizumab injection was $12.4 \pm 4.7$ (range 4-24) weeks. Of 127 eyes, 12 (9.4\%) developed IOI consisting of anterior chamber cells and/or vitreous cells, with retinal vasculitis documented in 4 eyes $(3.1 \%)$ and retinal vascular occlusion in 2 eyes (1.6\%) (Table 1). The IOI was noted after the first injection in 9 eyes at a mean of $23.2 \pm$ 9.3 (range 10-36) days post-injection; in the remaining 3 eyes, it occurred after the second or third injections. Rates of IOI were similar for treatment-naive cases $(9.3 \%)$ and switched cases $(9.5 \%)$, and were not higher in women (Table 2). IOI was treated with topical corticosteroids $(0.1 \%$ betamethasone eyedrops) in all eyes and additional sub-Tenon's injection of triamcinolone acetonide $(20 \mathrm{mg})$ in the 4 eyes with retinal vasculitis. No patient received systemic corticosteroids. Active inflammation resolved within 2 months in all patients. Although the retinal vascular occlusion observed in 2 eyes was located outside the vascular arcades, visual acuity decreased markedly from 74 to 35 Early Treatment of Diabetic Retinopathy Study letters then improved to 65 letters in 1 month for one eye, and decreased from 59 to 50 letters then improved to 65 letters in 1 month for the other eye.

Overall, the SRC found IOI in $4.6 \%$ of patients, retinal vasculitis in $3.3 \%$, and retinal vascular occlusion in $2.1 \%$. However, among 101 Japanese patients enrolled in the HAWK study, the rates were 2- to 3-fold higher; IOI in $12.9 \%$, retinal vasculitis in $9.9 \%$, and retinal vascular occlusion in $4.95 \%$ [5]. In addition, Heier et al. reported that female gender was associated with higher risk for IOI [4]. Previous case reports of IOI associated with brolucizumab were also predominantly in women [6]. The reasons for higher rates of inflammatory adverse effects in Japanese or women have yet to be delineated.

Because Japanese patients may be at higher risk, we believe it is important to report our early experience with brolucizumab over our first 6 months of use. We found IOI rates to be between 9 and $10 \%$, still high but slightly lower than reported by the SRC for Japanese trial patients. The majority $(75 \%)$ occurred after the first injection, and one-third developed retinal vasculitis or retinal vascular occlusion.

Acknowledgements Japan AMD Research Consortium: Taiji Hasegawa, $\mathrm{MD}, \mathrm{PhD}$, Tomohiro Iida, MD, PhD, Takahiko Izumi, MD, Moeko Kawai, MD, Ichiro Maruko, MD, $\mathrm{PhD}$, and Ruka Maruko, MD, $\mathrm{PhD}$ (Department of Ophthalmology, Tokyo Women's Medical University, Japan); Makiko Nakayama, MD, PhD, Annabelle A. Okada, MD, PhD, and Akiko Yamamoto, MD, PhD (Department of Ophthalmology, Kyorin
Table 2 Characteristics by patient gender of treatment-naive and switched eyes that developed intraocular inflammation after intravitreal brolucizumab injection

\begin{tabular}{llll}
\hline Treatment-naive & Total patients $(n=43)$ & Men $(n=36)$ & Women $(n=7)$ \\
IOI & $4 / 43(9.3 \%)$ & $3 / 36(8.3 \%)$ & $1 / 7(14.3 \%)$ \\
IOI with retinal vasculitis & $1 / 43(2.3 \%)$ & $1 / 36(2.8 \%)$ & $0 / 7(0 \%)$ \\
$\begin{array}{c}\text { IOI with retinal vasculitis and } \\
\text { retinal vascular occlusion }\end{array}$ & $0 / 43(0 \%)$ & $0 / 36(0 \%)$ & $0 / 7(0 \%)$ \\
Switched & Total patients $(n=84)$ & Men $(n=73)$ & Women $(n=11)$ \\
IOI & $8 / 84(9.5 \%)$ & $7 / 73(9.6 \%)$ & $1 / 11(9.1 \%)$ \\
IOI with retinal vasculitis & $3 / 84(3.6 \%)$ & $3 / 73(4.1 \%)$ & $0 / 11(0 \%)$ \\
IOI with retinal vasculitis & $2 / 84(2.4 \%)$ & $2 / 73(2.7 \%)$ & $0 / 11(0 \%)$ \\
$\quad$ and retinal vascular occlusion & & & \\
\hline
\end{tabular}

Treatment-naive $=$ eyes without any prior treatment

Switched $=$ eyes previously treated with other anti-VEGF agents

VEGF $=$ vascular endothelial growth factor

IOI = intraocular inflammation 
University School of Medicine, Japan). Hideki Koizumi, MD, PhD, Tamaki Tamashiro, MD, Nobuhiro Terao, MD, PhD, Sorako Wakugawa, MD (Department of Ophthalmology, Graduate School of Medicine, University of the Ryukyus, Japan); Ryusaburo Mori, MD, PhD, Hajime Onoe, MD, Koji Tanaka, MD, PhD, Yu Wakatsuki, MD, PhD (Department of Ophthalmology, Nihon University School of Medicine, Japan). Kanako Itagaki, MD, Akihito Kasai, MD, Masashi Ogasawara, MD, Tetsuju Sekiryu, MD, PhD, Hiroaki Shintake, MD, and Yukinori Sugano, MD, $\mathrm{PhD}$ (Department of Ophthalmology, Fukushima Medical University, Japan).

\section{Declarations}

Ethics approval This was a retrospective study, and the procedures used conformed to the tenets of the Declaration of Helsinki. The Institutional Review Boards of Kyorin University, Fukushima Medical University, Nihon University, Tokyo Women's Medical University, and University of the Ryukyus approved the procedures used. Informed consent was obtained from all individual participants included in the study.

Conflict of interest Dr Maruko reported grants from JSPS KAKENHI (Grant Number JP20K09781); personal fees from Alcon, Bayer, Canon, Nidek, Novartis, Santen, Senju, and Topcon outside the submitted work.

Dr Okada reported consulting fees from Astellas, Bayer, Biocon Biologics, Daiichi Sankyo, HOYA, Kowa, and Novartis; personal support from Abbvie, Alcon, Bayer, Mitsubishi Tanabe, Novartis, Pfizer, Santen, and Senju outside the submitted work.

Dr Iida reported consulting fees from Bayer and Chugai; personal fees from AMO, Alcon, Bayer, Canon, HOYA, JFC, Kowa, Nikon, Nidek, Novartis, Otsuka, Pfizer, Santen, Senju, and Topcon outside the submitted work.

Open Access This article is licensed under a Creative Commons Attribution 4.0 International License, which permits use, sharing, adaptation, distribution and reproduction in any medium or format, as long as you give appropriate credit to the original author(s) and the source, provide a link to the Creative Commons licence, and indicate if changes were made. The images or other third party material in this article are included in the article's Creative Commons licence, unless indicated otherwise in a credit line to the material. If material is not included in the article's Creative Commons licence and your intended use is not permitted by statutory regulation or exceeds the permitted use, you will need to obtain permission directly from the copyright holder. To view a copy of this licence, visit http://creativecommons.org/licenses/by/4.0/.

\section{References}

1. Dugel PU, Singh SR, Koh A et al (2020) HAWK and HARRIER: 96-week outcomes from the phase 3 trials of brolucizumab for neovascular age-related macular degeneration. Ophthalmology. https://doi.org/10.1016/j.ophtha.2020.06.028

2. Novartis AG (2020) Novartis provides update on use and safety of Beovu (brolucizumab). Available at: https://www.brolucizumab. info/. Accessed 10 December 2020

3. Monés J, Srivastava SK, Jaffe GJ et al (2020) Risk of inflammation, retinal vasculitis and retinal occlusion-related events with brolucizumab: post-hoc review of HAWK and HARRIER. Ophthalmology S0161-6420(20):31075-31077. https://doi.org/10. 1016/j.ophtha.2020.11.011

4. Heier JS, Rosenbaum JT, Barakat MR et al. (2020) Assessing characteristics of patients with or without intraocular inflammation (IOI) in the brolucizumab treatment arms from the HAWK and Harrier, phase 3 studies. Presented at the Annual Meeting of the American Academy of Ophthalmology (virtual) November 14-17

5. Iida T, Takahashi K, Kinfemichael G, Ogura Y (2020) Subpopulation analysis of Japanese patients from brolucizumab HAWK study. Presented at the 74th Annual Congress of Japan Clinical Ophthalmology (virtual) October 15-18

6. Baumal CR, Spaide RF, Vajzovic L et al (2020) Retinal vasculitis and intraocular inflammation after intravitreal injection of brolucizumab. Ophthalmology 127(10):1345-1359. https://doi.org/ 10.1016/j.ophtha.2020.04.017

Publisher's note Springer Nature remains neutral with regard to jurisdictional claims in published maps and institutional affiliations. 